\title{
BMJ open Detailed protocol for the lifestyle intervention in the BeWEL randomised controlled trial of weight loss in adults who have had a colorectal adenoma
}

\author{
Stephen Caswell, ${ }^{1}$ Angela M Craigie, ${ }^{1}$ Jane Wardle, ${ }^{2}$ Martine Stead, ${ }^{3}$ \\ Annie Anderson ${ }^{1}$
}

To cite: Caswell S, Craigie AM, Wardle J, et al. Detailed protocol for the lifestyle intervention in the BeWEL randomised controlled trial of weight loss in adults who have had a colorectal adenoma. BMJ Open 2012;2: e001276. doi:10.1136/ bmjopen-2012-001276

- Prepublication history for this paper is available online. To view this file please visit the journal online (http://dx. doi.org/10.1136/ bmjopen-2012-001276).

Received 5 April 2012 Accepted 26 April 2012

This final article is available for use under the terms of the Creative Commons Attribution Non-Commercial 2.0 Licence; see http://bmjopen.bmj.com

\footnotetext{
${ }^{1}$ Centre for Research into Cancer Prevention and Screening, Medical Research Institute, Population Health Sciences Division, University of Dundee, Dundee, UK

${ }^{2}$ Health Behaviour Unit, Department of Epidemiology and Public Health, University College London, London, UK ${ }^{3}$ Institute for Social Marketing, Stirling Management School, University of Stirling and the Open University, Stirling, UK

Correspondence to Professor Annie Anderson; a.s.anderson@dundee.ac.uk
}

\section{ABSTRACT}

Introduction: The BeWEL study is aimed at assessing the impact of a personalised lifestyle programme on body weight in people at risk of developing colorectal adenomas. The study is a two-arm multicentre randomised controlled trial comparing the BeWEL lifestyle programme against usual care. Over 12 months, 316 people who have had a colorectal adenoma removed through the national screening programme will be randomised to provide $80 \%$ power to detect a weight loss (primary outcome) of $7 \%$ over 12 months.

Methods: The 12-month intervention will be delivered by lifestyle counsellors via three face-to-face visits followed by nine monthly telephone support calls. Consultant endorsement for the study will be stressed. An individualised caloric prescription based on estimates for weight maintenance $-600 \mathrm{kcal}$ will be calculated. Motivational interviewing techniques will be used to identify personal motivations for weight change and ways to improve perceived self-efficacy. The programme will utilise personalised diet and physical activity data from baseline measures to set behavioural goals. A range of behavioural strategies will be employed to support lifestyle change including goal setting, identifying specific implementation intentions, self-monitoring and feedback. Emphasis will be placed on self-monitoring body weight, and weighing scales will be provided. Programme acceptability will be explored postintervention with indepth interviews. Compliance and impact will be assessed by baseline and follow-up measures of diet by self-report, activity by accelerometry and anthropometry.

Ethics and dissemination: Ethical approval has been obtained from the Tayside Committee on Medical Research Ethics. Dissemination of results will focus on publications in peer-reviewed journals, presentations at national/international cancer meetings and NHS groups. In addition, the work will be communicated to the public through forums such at The Scottish Cancer Prevention Network (http://www.

cancerpreventionscotland.co.uk/). The trial is registered with Current Controlled Trials (International Standard Randomised Controlled Trials No: ISRCTN53033856).

\section{ARTICLE SUMMARY}

Article focus
- Design of diet and physical activity intervention
for weight loss.
- Detailed protocol of content and delivery of
intervention.
Key messages
- Process of combining educational, motivational
and behavioural strategies.
- Developing the teachable moment in the colo-
rectal cancer screening setting.
Strengths and limitations of this study
- Minimal contact intervention over 12 months.
- Potential change in control group through study
involvement.

\section{INTRODUCTION}

Colorectal cancer (CRC) is the third most commonly diagnosed cancer in the UK. ${ }^{1}$ Most cases occur in people over 50 years and CRC often coexists with other diet-related disorders including obesity, type 2 diabetes mellitus and cardiovascular disease. ${ }^{2-4}$ These diseases share risk factors related to the metabolic syndrome including high body mass index, abnormal lipids and markers of insulin resistance indicating common aetiological pathways. ${ }^{5}$

The World Cancer Research Fund (WCRF) (2007) review of Food, Nutrition, Physical Activity and the Prevention of Cancer provides comprehensive evidence on dietand obesity-related risk factors and CRC. ${ }^{6}$ The main (convincing level) factors identified by WCRF to increase risk were high body fat, red and processed meat and alcohol intake, whereas high levels of physical activity and foods containing fibre were factors that (probably) decreased risk. 
Weight gain in adulthood is associated with the development and recurrence of colorectal adenomas (premalignant lesions), while weight loss is associated with reduced recurrence rates. ${ }^{7-9}$ Therefore, it would seem prudent to recommend weight loss (through increased physical activity and dietary adjustment) to overweight adults who have experienced an adenoma in order to minimise the risk of CRC and other related co-morbidities. While surveillance colonoscopy is offered to patients who have had adenomas, colonoscopy procedures may still miss adenomas, and several studies have reported interval cancers diagnosed between examinations. ${ }^{10-12}$ Current evidence suggests that the risk of new adenomas is around $40 \%$ after 3 years; although this may be higher in the morbidly obese. ${ }^{13}$ Furthermore, the underlying modifiable risk factors that influence the development of new adenomas remain after colonoscopy.

The BeWEL study design and evaluation protocol are described elsewhere. ${ }^{14}$ In brief, this is a two-arm, multicentre randomised controlled trial comparing the BeWEL lifestyle programme (targeting behaviour change with regards to diet, physical activity and weight loss) against usual care. The intervention will be delivered over 12 months and aims to achieve complete data from 266 adults aged 50-74 years who have undergone colonoscopy for adenoma removal. The primary outcome is change in body weight.

The behavioural context for the intervention builds on the observation that programmes which target high-risk groups are more effective than those targeting the population at large ${ }^{15}$ In addition, individuals who have had a health scare (eg, diagnosis of an adenoma) may be in a 'teachable moment' in which they are more motivated to engage with and adhere to lifestyle advice. ${ }^{16}$ This may depend on them experiencing an increase in perceived risk of disease (with expectations of negative consequences) and having an emotional response that triggers a redefinition of their self-image or role. ${ }^{17}$

The lifestyle goals of the BeWEL intervention were based on the diabetes prevention trials which have shown that lifestyle interventions that achieve a weight loss of $7 \%$ of initial body weight and at least $150 \mathrm{~min} /$ week of moderate intensity activity in adults with a body mass index $>25 \mathrm{~kg} / \mathrm{m}^{2}$ reduce the incidence of type 2 diabetes mellitus. ${ }^{18-21}$ The behavioural characteristics of the intervention delivery were largely based on the US Diabetes Prevention Programme, ${ }^{22}$ with the addition of emphasis on the importance of regular self-weighing that is widely associated with greater weight loss and weight prevention. ${ }^{23} 24$

The final design of the intervention protocol was informed by formative social marketing research with the client group, ${ }^{25}$ evidence on behaviour change (as described above) and practical (resource) considerations. The aim of the current paper is to detail the procedures and content of the lifestyle programme used with the intervention group as described in the final study protocol. ${ }^{14}$

\section{METHODS}

The BeWEL study will recruit 316 participants who have had a colorectal adenoma removed following their participation in the Scottish Bowel Screening programme. Of these, $158(50 \%)$ will be randomised to the intervention arm of the BeWEL trial. ${ }^{14}$ The intervention is designed to involve multiple contacts with Lifestyle Counsellors (LC's) over a 12-month period, and all participants will be invited to identify a partner or friend to provide support. Three face-to-face visits in the first 3 months will be followed with nine telephone support calls spaced equally until completion of the study with follow-up assessments being taken at 12 months.

Any serious adverse events (SAEs) experienced by participants will be reported to the study sponsor, NHS Tayside Research and Development (administration), Trial Management Committee, Trial Steering Committee (TSC), Data Monitoring and Ethics Committee (DMEC) and the participants' General Practitioner. In the event that an SAE is considered to be related to the trial intervention, clinical judgement and the participant's preference will inform any decision whether the participant will be withdrawn from the trial or may withdraw electively. Under no circumstances, initiated by the occurrence of an SAE or otherwise, is a participant permitted to change group allocation. All SAEs and any consequent decisions for participant retention are reported appropriately. A review of all adverse events and SAEs will also be undertaken at regular intervals by the DMEC to ensure any differential rate between groups is identified. Full details of evaluation methods of the study, for which the primary outcome is body weight, are provided elsewhere. ${ }^{14}$

LCs will be trained to deliver the intervention protocol that focuses on four strategies for assisting behaviour change. First, the LCs will aim to increase knowledge about why the changes are advisable, second, the magnitude and nature of change required will be discussed, third, techniques aimed at motivating change will be used and finally strategies to improve self-efficacy about changing diet and activity will be provided.

After providing written informed consent, participants will undertake their first intervention visit. The LCs will begin their introduction by discussing the process through which CRC typically develops, that is, the adenoma-carcinoma sequence. ${ }^{26}$ The counsellors will highlight the importance of diet, activity and body weight in the prevention of CRC and also emphasise how weight loss might reduce the risk of other diseases or comorbidities. It will then be made clear to participants that the principal aim of the study is to promote weight loss through diet and activity. Before addressing specific components of the intervention, participants will be reminded that the changes being promoted are endorsed by the senior hospital consultants as indicated in the study invitation letter.

The target goal of a $7 \%$ reduction in body weight will be communicated at the first contact. An individualised energy prescription for weight loss will be identified in 
three steps. Initially, their requirements for weight maintenance will be calculated using Schofield equations ${ }^{27}$ incorporating body weight, gender and age. This will then be multiplied by their current physical activity level before a caloric restriction of $-600 \mathrm{kcal}$ is applied. The composition of the diet will be in line with current healthy eating advice (with caution over consumption of excess red and processed meat and limiting intake of energy-dense food and drinks) and increased physical activity. No pharmacological agents will be provided or promoted.

The general educational components of healthy eating and active living will initially be explained using the British Heart Foundation (BHF) (2010) booklet 'So you want to lose weight for good' (which includes the Food Standards Agency 'Eatwell' plate model (the national food guide). ${ }^{28}$ Portion guidance and information on energy-dense food and drinks (highlighting fast foods and sugary drinks) will be provided with reference to the information in the BHF booklet. With respect to physical activity, demonstrations will be given on 'brisk walking' and a pedometer provided for self-monitoring. The translation of $7 \%$ weight loss will be provided as a personal weight loss target for the 12-month period. This will include guidance on a personalised $-600 \mathrm{kcal}$ energy-deficit diet (based on estimated Basal Metabolic Rate), provided on the basis of food group portion sizes and portion frequencies. Options on following this completely (eg, starting on $-600 \mathrm{kcal}$ ) from day 1 or building up to $-600 \mathrm{kcal}$ will be discussed with reference to the weight loss requirements over a 12-month period.

Motivational interviewing ${ }^{29}$ will be utilised to explore self-assessed confidence, ambivalence and personal values concerning weight change. A 24-h recall of dietary intake will be taken to promote discussion around current diet and allow counsellors to introduce the concept of personalised dietary change. Study participants will have worn a SenseWear $\mathrm{Pro}_{3}$ physical activity monitor (Body Media, Pittsburgh, Pennsylvania, USA) for 7 days to provide baseline physical activity records (also worn by the usual care group), prior to being visited by the LC. The output from the monitors will be utilised to provide feedback on current activities and to promote discussion around opportunities to increase leisure time activity where possible.

To assist change in both diet and physical activity, participants will be encouraged to focus on one topic (diet or physical activity) for the remainder of visit one, and the remaining topic on visit two, generally advising that the strongest area of existing success is likely to be the best to begin with. To aid improvements in selfefficacy, participants will be encouraged to identify specific behavioural goals ${ }^{30}$ and make short-term specific implementation intentions. ${ }^{31}$ Success or failure with these goals will be discussed at follow-up visits. Selfmonitoring will also be encouraged, and participants will be presented with body weight scales for weekly weighing, pedometers to monitor daily step counts and $\log$ books. A number of behavioural and re-enforcement techniques will be employed in this part of the counselling session including tool kits to assist change, practical discussions on food preparation (or equipment demonstrations) and self-recording sheets for the specific implementation intentions identified. Tool kits will include items for loan including kitchen gadgets such as salad spinners and hand blenders and physical activity tools such as steppers, hand weights, hula hoops, exercise DVDs and walking poles. In addition, to encourage loyalty to the study, all participants will be given tools with the BeWEL logo: a water bottle to reinforce the message to reduce sugary drink intake and a fabric bag for transporting scales home and/or to act as reminder for healthy eating while shopping.

The first session will finish with a return to weight matters and instructions for self-monitoring and recording of weight will be given. Contact details for professional support will be provided and the next appointment made. Visits 2 and 3 will have similar formats, checking well-being discussing and providing feedback on progress and experiences, exploring areas of difficulty and providing encouragement. Visit 2 will also encourage a focus on the second topic area (diet or activity) not selected in visit 1 . The content of all visits is presented in table 1 .

By the end of visit 3, all participants will have identified a specific set of personalised diet and activity implementation intentions and weight loss goals for the remainder of the study.

The remainder of the intervention will be delivered by telephone (table 2). Nine further telephone calls from 3 to 12 months will be completed before participants return to the research centre for follow-up measures. LCs will continue to support BeWEL participants in their attempts to lose the target $7 \%$ body weight. Participants who do achieve this target but who remain overweight will be encouraged to continue the weight loss programme. Participants who have met their target weight loss (and are no longer overweight) will be encouraged to adopt a weight maintenance approach.

Follow-up calls will begin with a general introduction about mental and physical well-being, and LC's will attempt to elicit participant's views on making lifestyle change. LC's will be responsible for checking participant's progress since visit 3 and the first follow-up at 3 months, discussing areas of success and difficulty. LC's will provide the participant with further verbal (and where appropriate written) and personalised lifestyle advice to promote optimal dietary intake, physical activity and weight loss. Personalised goals will be agreed and updated through discussion with the participant, and the LC's will keep records of these to provide personalised feedback and continuity through to followup at 12 months.

\section{Protocol adherence and monitoring}

LCs will keep participant notes recording the application of the above procedures, and these will be reported to 
Table 1 Delivery and content of counsellor visits (contacts 1-3)

\begin{tabular}{|c|c|c|c|}
\hline & Visit 1 & Visit 2 & Visit 3 \\
\hline Contact & Face-to-face & Face-to-face & Face-to-face \\
\hline Time line & $\begin{array}{l}\text { Following baseline } \\
\text { assessment }\end{array}$ & Week 6-8 & 3 months \\
\hline Duration & $90 \mathrm{~min}$ & $45 \min$ & $45 \min$ \\
\hline Who delivers & Trained counsellor & Trained counsellor & Trained counsellor \\
\hline $\begin{array}{l}\text { Intervention } \\
\text { location }\end{array}$ & Home/research centre & Home/research centre & Home/research centre \\
\hline Social support & $\begin{array}{l}\text { Invited friend/partner/ } \\
\text { family member }\end{array}$ & $\begin{array}{l}\text { Invited friend/partner/ } \\
\text { family member }\end{array}$ & $\begin{array}{l}\text { Invited friend/partner/ } \\
\text { family member }\end{array}$ \\
\hline Introduction & $\begin{array}{l}\text { Check nurse } \\
\text { assessment } \\
\text { Importance of } \\
\text { lifestyle change } \\
\text { - Consultant endorsement } \\
\text { - Identify 12-month weight } \\
\text { loss target }\end{array}$ & $\begin{array}{l}\text { Current well-being } \\
\text { Experience of making } \\
\text { change } \\
\text { Importance of modest } \\
\text { change } \\
\text { Building towards } \\
\text { 12-month weight } \\
\text { loss target }\end{array}$ & $\begin{array}{l}\text { Current well-being } \\
\text { Experience of making } \\
\text { change } \\
\text { Importance of modest } \\
\text { change } \\
\text { Building towards } \\
\text { 12-month weight loss target }\end{array}$ \\
\hline $\begin{array}{l}\text { Motivational } \\
\text { approaches }\end{array}$ & $\begin{array}{l}\text { 24-h dietary recall/activity } \\
\text { assessment } \\
\text { Identify perceived } \\
\text { diet/activity challenges } \\
\text { Identify self-assessed } \\
\text { motivations, confidence, } \\
\text { ambivalence and personal } \\
\text { value regarding weight } \\
\text { change }\end{array}$ & $\begin{array}{l}\text { Identify self-monitored } \\
\text { weight } \\
\text { Provide feedback } \\
\text { Provide encouragement } \\
\text { Identify self-assessed } \\
\text { motivations, confidence, } \\
\text { ambivalence and personal } \\
\text { values rechange }\end{array}$ & $\begin{array}{l}\text { Identify self-monitored weight } \\
\text { Provide feedback } \\
\text { Provide encouragement } \\
\text { Identify confidence and } \\
\text { support needs }\end{array}$ \\
\hline $\begin{array}{l}\text { Education- } \\
\text { general }\end{array}$ & $\begin{array}{l}\text { Healthy eating and activity } \\
\text { principles } \\
\text { Portion size } \\
\text { Energy-dense food and } \\
\text { drinks } \\
\text { Breakfast meals and } \\
\text { snacks } \\
\text { Activity and inactivity } \\
\text { Demonstration of brisk } \\
\text { walking + pedometer }\end{array}$ & $\begin{array}{l}\text { Discuss experience of } \\
\text { changing diet and activity } \\
\text { referring back to perceived } \\
\text { challenges at visit } 1 \text {. } \\
\text { Check for queries or areas } \\
\text { of confusion or elaboration } \\
\text { Discuss walking + pedometer }\end{array}$ & $\begin{array}{l}\text { Discuss experience of changing } \\
\text { diet and activity referring back } \\
\text { to perceived challenges at } \\
\text { visits } 1 \text { and } 2 \\
\text { Check for queries or areas of } \\
\text { confusion or elaboration } \\
\text { Discuss walking + pedometer }\end{array}$ \\
\hline $\begin{array}{l}\text { Education- } \\
\text { personalised }\end{array}$ & $\begin{array}{l}\text { Structured weight loss } \\
\text { programme }-600 \mathrm{kcal} \\
\text { diet prescription plan }\end{array}$ & $\begin{array}{l}\text { Discuss progress towards } \\
\text { achieving }-600 \mathrm{kcal} \text { diet }\end{array}$ & $\begin{array}{l}\text { Discuss progress towards } \\
\text { achieving }-600 \mathrm{kcal} \text { diet }\end{array}$ \\
\hline $\begin{array}{l}\text { Behavioural } \\
\text { and } \\
\text { re-enforcement } \\
\text { techniques } \\
\text { DIET OR } \\
\text { ACTIVITY }\end{array}$ & $\begin{array}{l}\text { Introduce diet or activity } \\
\text { focus } 1\end{array}$ & $\begin{array}{l}\text { Discuss self-monitoring } \\
\text { of focus } 1 \\
\text { Provide positive feedback } \\
\text { Identify challenges } \\
\text { Discuss maintenance } \\
\text { Introduce diet or activity } \\
\text { focus } 2\end{array}$ & $\begin{array}{l}\text { Discuss self-monitoring of } \\
\text { focus } 2 \\
\text { Provide positive feedback } \\
\text { Identify challenges } \\
\text { Discuss maintenance of } \\
\text { foci } 1 \text { and } 2 \\
\text { Negotiate key long-term diet } \\
\text { and activity goals based on: } \\
\text { Perceived achievements } \\
\text { Summarise success }\end{array}$ \\
\hline $\begin{array}{l}\text { Behavioural and } \\
\text { re-enforcement } \\
\text { techniques } \\
\text { WT MANAGEMENT }\end{array}$ & $\begin{array}{l}\text { Provide body weight scales } \\
\text { Explanation of self-monitoring } \\
\text { procedures } \\
\text { Remind about 12-month goal }\end{array}$ & $\begin{array}{l}\text { Re-enforce body weight } \\
\text { techniques }\end{array}$ & $\begin{array}{l}\text { Check body weight scales } \\
\text { and the need for continued } \\
\text { monitoring }\end{array}$ \\
\hline Professional support & $\begin{array}{l}\text { Provide tel and email contact } \\
\text { details } \\
\text { Identify next two appointments }\end{array}$ & $\begin{array}{l}\text { Confirm next appointment } \\
\text { and identify date for call } 1\end{array}$ & $\begin{array}{l}\text { Confirm call } 1 \text { and identify } \\
\text { date for call } 2\end{array}$ \\
\hline
\end{tabular}


Table 2 Telephone intervention for contacts 4-12

\begin{tabular}{|c|c|}
\hline & Contacts $4-12$ \\
\hline Contact & Telephone \\
\hline Time line & $\begin{array}{l}\text { Following on from third face-to-face contact until 12-month follow-up } \\
\text { assessment }\end{array}$ \\
\hline Duration & $10-15 \mathrm{~min}$ \\
\hline Who delivers & Trained counsellor \\
\hline Introduction & $\begin{array}{l}\text { General exchange about mental and physical health } \\
\text { Elicit participant's overview on progress and change made } \\
\text { Re-enforce importance of modest behaviour change for health benefit } \\
\text { Importance of change and building towards } 12 \text {-month weight loss target. } \\
3 \text { months gone but } 9 \text { months to continue improvement. }\end{array}$ \\
\hline Motivational approaches & $\begin{array}{l}\text { Check self-monitoring records } \\
\text { Identify perceived diet/activity challenges } \\
\text { Identify self-assessed motivations, confidence, ambivalence and personal } \\
\text { value reweight change }\end{array}$ \\
\hline Informing change & $\begin{array}{l}\text { Re-enforce portion size guidance/energy-dense foods/energy-dense drinks } \\
\text { Importance of remaining active }\end{array}$ \\
\hline Personal goals (implementation intentions) & $\begin{array}{l}\text { Continue to focus on short-term implementation intentions and review these } \\
\text { at next call. }\end{array}$ \\
\hline Setting long-term goals & $\begin{array}{l}\text { Identify perceived achievements and summarise success } \\
\text { Re-evaluate confidence, motivation and importance of changes made }\end{array}$ \\
\hline Professional support & $\begin{array}{l}\text { Make appointment for next telephone call but reiterate you can respond to } \\
\text { questions before this call as they arise. }\end{array}$ \\
\hline
\end{tabular}

the study team as an indirect check on intervention fidelity and to encourage protocol adherence. Regular meetings will be held with all counsellors to discuss challenges in protocol adherence and possible solutions to address problems, which will be re-assessed at followup workshops. A protocol minor amendment has also enabled approval to be given for research team members to be present at face-to-face intervention sessions and to record telephone counselling.

Programme acceptability will be explored after intervention with indepth exit interviews (undertaken by staff not involved with programme delivery) with a random sample of 30 intervention participants. Interviews will cover participants' initial expectations and motivations regarding the programme, the extent to which these were met or not by their subsequent experiences and factors influencing their ability to make the recommended lifestyle changes. ${ }^{14}$ A thematic analysis of interview transcripts will be undertaken, exploring such themes as what factors influence decisions to engage in the programme, how uptake is influenced by socioeconomic status, the practical barriers and opportunities for facilitating physical activities and changes in dietary habits and the perceived acceptability of the programme to participants and families.

The impact of specific component parts on outcomes will not be assessed, but reported compliance with diet and physical activity goals will be available from postintervention measures. $^{14}$

\section{ETHICS AND DISSEMINATION}

Ethical approval for the intervention content was obtained from the Tayside Committee on Medical Research Ethics.
Financial support is provided by the National Prevention Research Initiative (http://www.npri.org.uk), grant award number G0802030. National Prevention Research Initiative is a national research initiative administered by the Medical Research Council made up of the following funding partners: Alzheimer's Research Trust; Alzheimer's Society; Biotechnology and Biological Sciences Research Council; Cancer Research UK; Chief Scientist Office, Scottish Government Health Directorate; Department of Health; Diabetes UK; Economic and Social Research Council; Engineering and Physical Sciences Research Council; Health \& Social Care Research \& Development Office for Northern Ireland; Medical Research Council; Welsh Assembly Government and WCRF. In addition, further financial support is also being provided by the NHS Research Scotland to carry out this work. The study is sponsored by the University of Dundee.

Governance for the study is provided by a TSC with an independent Chairperson, representatives from other academic institutions, non-governmental organisations (NGO), patient representatives and representatives from the sponsor and funding agency. However, decisions on study design, protocol amendments, data collection, management, analysis and data interpretation, publication policy and report writing and submission are made by the Trial Management Committee subject to approval by TSC aided by an independent DMEC.

The detailed intervention protocol provides a standardised approach to intervention design, delivery and content for use in diet, physical activity and weight loss trials. The rationale for the total amount of contact time (5.25 h over a 12-month period) with counsellors would be similar to monthly weight management 
appointments in NHS (primary care) but less than commercial slimming clubs. Minimal contact enables costs to be minimised but professional support to be retained.

Group work was not considered because of the geographical spread of the regions in which the trial is being carried out and the subject face-to-face time burden. Minimal contact approaches such as phone and email have been shown to produce promising results for weight loss with high-frequency calls from a health professional producing similar results to high-frequency face-to-face lifestyle modification counselling. ${ }^{32} 33$

The content of the intervention was based on current guidelines for weight management from the Scottish Intercollegiate Guidelines Network ${ }^{34}$ that recommends a combination of physical activity, diet and behavioural therapy components. The behavioural strategies used draw on evidence for successful dietary changes from Ammerman $e t a l^{35}$ and weight loss management from the National Institute for Health and Clinical Excellence. ${ }^{36}$

The fidelity of the intervention content and delivery will inevitably vary by the individual style of each LC, but training sessions have emphasised the need to deliver all components but modify to suit the participants' individual circumstances, for example, disability, economic circumstances or learning difficulties. While family/ friend support is recommended, it is recognised that this will not be possible to access in all cases.

The ease of undertaking all contacts with participants, delivering the intervention components and feedback from participants will provide insight to the practical acceptability of this theory-based practice-focused intervention design.

The dissemination of the trial findings will principally be carried out through publications in peer-reviewed journals, presentations at national/international cancerfocused meetings and to NHS groups including the Scottish Cancer Task Force. In addition, the work will be communicated to the public through forums such at The Scottish Cancer Prevention Network (http://www. cancerpreventionscotland.co.uk/).

Contributors SC has prepared materials for intervention inclusion, advised on implementation strategies and drafted manuscript, AMC has advised on physical activity measures and tools, overall package design and manuscript drafting. JW has contributed advice on behavioural techniques, educational strategies and overall design components. MS has contributed to specific translation details from formative work into overall intervention, focusing on educational material and all communications. AA is the principal investigator for the study and has over seen the intervention design, development and implementation and manuscripts drafting and editing. All authors have contributed to intervention design, study design, final protocol and manuscript editing.

Funding The National Prevention Research Initiative (NPRI).

Competing interests None.

Ethics approval Ethical approval has been obtained from the Tayside Committee on Medical Research Ethics.

Provenance and peer review Not commissioned; internally peer reviewed.

Data sharing statement No additional data available.

\section{REFERENCES}

1. Cancer Research UK. Cancerstats. http://info.cancerresearchuk.org/ cancerstats/types/bowel/

2. Brown BW, Brauner C, Minnotte MC. Noncancer deaths in white adult cancer patients. J Natl Cancer Inst 1993;85:979-87.

3. Baade PD, Fritschi L, Eakin EG. Non-cancer mortality among people diagnosed with Cancer. Cancer Causes Control 2006;17(Suppl 3):287-97.

4. Hawkes AL, Lynch BM, Owen N, et al. Lifestyle factors associated concurrently and prospectively with co-morbid cardiovascular disease in a population based cohort of colorectal cancer survivors. Eur J Cancer 2011;47(Suppl 2):267-76.

5. Giovannuci E. Metabolic syndrome, hyperinsulinemia, and colon cancer: a review. Am J Clin Nutr 2007;86(Suppl 3):s836-42.

6. World Cancer Research Fund/American Institute for Cancer Research. Food, Nutrition, Physical Activity, and the Prevention of Cancer: A Global Perspective. Washington, DC: AICR, 2007.

7. Sedjo RL, Byers T, Levin TR, et al. Change in body size and the risk of colorectal adenomas. Cancer Epidemiol Biomarkers Prev 2007;16 (Suppl 3):526-31.

8. Jacobs ET, Martínez ME, Alberts DS, et al. Association between body size and colorectal adenoma recurrence. Clin Gastroenterol Hepatol 2007;5(Suppl 8):982-90.

9. Yamaji $\mathrm{Y}$, Okamoto $\mathrm{M}$, Yoshida $\mathrm{H}$, et al. The effect of body weight reduction on the incidence of colorectal adenoma. Am J Gastroenterol 2008;103(Suppl 8):2061-7.

10. Robertson DJ, Greenberg ER, Beach M, et al. Colorectal cancer in patients under close colonoscopic surveillance. Gastroenterology 2005;129:34-41.

11. Leung K, Pinsky $\mathrm{P}$, Laiyemo $\mathrm{AO}$, et al. Ongoing colorectal cancer risk despite surveillance colonoscopy: the Polyp Prevention Trial Continued Follow up Study. Gastrointest Endosc 2010;71:111-17.

12. Cottet V, Jooste V, Fournel I, et al. Long term risk of colorectal cance after adenoma removal: a population based-cohort study. Gut. Published Online First: 22 November 2011. doi:10.1136/gutjnl-2011 300295

13. Laiyemo AO, Murphy G, Albert PS, et al. Postpolypectomy colonoscopy surveillance guidelines: predictive accuracy for advanced adenoma at 4 years. Ann Intern Med 2008;148:419-26.

14. Craigie AM, Caswell S, Paterson C, et al. Study protocol for BeWEL: the impact of a body weight and physical activity intervention on adults at risk of developing colorectal adenomas. BMC Public Health 2011;11:184.

15. Roe $\mathrm{L}$, Hunt $\mathrm{P}$, Bradshaw $\mathrm{H}$, et al. Health Promotion Interventions to Promote Healthy Eating in the General Population: A Review. London, UK: Health Education Authority, 1997.

16. McBride CM, Puleo E, Pollak KI, et al. Understanding the role of cancer worry in creating a "teachable moment" for multiple risk factor reduction. Soc Sci Med 2008;66:790-800.

17. Lawson PJ, Flockie SA. Teachable moments for health behavio change: a concept analysis. Patient Educ Couns 2009;76:125-30.

18. Torjesen PA, Birkeland $\mathrm{KI}$, Anderssen SA et al. Lifestyle changes may reverse development of the insulin resistance syndrome. The Oslo Diet and Exercise Study: a randomized trial. Diabetes Care 1997;20(Suppl 1):26-31.

19. Tuomilehto J, Lindström J, Eriksson JG, et al. Prevention of type 2 diabetes mellitus by changes in lifestyle among subjects with impaired glucose tolerance. N Engl J Med 2001;344(Suppl 18):1343-50.

20. Knowler WC, Barrett-Connor E, Fowler SE, et al. Reduction in the incidence of type 2 diabetes with lifestyle intervention or metformin. N Engl J Med 2002;346:(Suppl 6):393-403.

21. Ratner R, Goldberg R, Haffner S, et al. Impact of intensive lifestyle and metformin therapy on cardiovascular disease risk factors in the diabetes prevention program. Diabetes Care 2005;28:(Suppl 4):888-94.

22. US Diabetes Prevention Programme. http://www.bsc.gwu.edu/dpp/ index.html

23. VanWormer JJ, French SA, Pereira MA, et al. The impact of regular self-weighing management: a systematic literature review. Int $J$ Behav Nutr Phys Act 2008;5:54.

24. VanWormer JJ, Martinez AM, Martinson BC et al Self-weighing promotes weight loss for obese adults. Am J Prev Med 2009;36 (Suppl 1):70-3.

25. Stead M, Eadie D, Caswell S, et al. Understanding the potential and challenges of adenoma treatment as a prevention opportunity: insights from the BeWEL formative study. Prev Med 2012:54:97-103.

26. Leslie A, Carey FA, Pratt NR, et al. The colorectal adenomacarcinoma sequence. Br J Surg 2002;89(Suppl 7):845-60.

27. Schofield WN. Predicting basal metabolic rate, new standards and review of previous work. Hum Nutr Clin Nutr 1985;39(Suppl 1): $5-41$. 
28. British Heart Foundation. So You Want to Lose Weight for Good. 2010. http://www.bhf.org.uk/

29. Rollnick S, Butler CC, Kinnersley P, et al. Motivational interviewing BMJ 2010;340:c1900.

30. Bandura A. Social Foundations of Thought and Action. New Jersey: Prentice-Hall, 1986.

31. Gollwitzer PM. Implementation intentions: strong effects of simple plans. Am Psychol 1999;54:493-503.

32. Van Wier MF, Ariëns GA, Dekkers JC, et al. ALIFE @Work: a randomised controlled trial of a distance counselling lifestyle programme for weight control among an overweight working population. BMC Public Health 2006;6:140.
33. Digenio AG, Mancuso JP, Gerber RA, et al. Comparison of methods for delivering a lifestyle modification program for obese patients: a randomized trial. Ann Intern Med 2009,150:(Suppl 4) 255-62.

34. Scottish Intercollegiate Guidelines Network (SIGN). Management of Obesity. 2010. http://www.sign.ac.uk/pdf/sign115.pdf

35. Ammerman A, Lindquist C, Hersey J. Evidence Report on the Efficacy of Interventions to Modify Dietary Behaviour Related to Evidence Risk. Rockville, MD: Agency for Healthcare Research and Quality, 2001.

36. National Institute for Health and Clinical evidence. Obesity, the Prevention, identification. 2006. http://nice.org.uk/CG43 